\title{
Risk factors for incident depression in patients at first acute coronary syndrome
}

\author{
Paolo Ossola ${ }^{\mathrm{a}, \mathrm{b}, *}$, Francesca Paglia $^{\mathrm{a}}$, Annalisa Pelosi ${ }^{\mathrm{c}}$, Chiara De Panfilis ${ }^{\mathrm{a}, \mathrm{b}}$, Giulio Conte ${ }^{\mathrm{d}}$, \\ Matteo Tonna ${ }^{\mathrm{b}}$, Diego Ardissino ${ }^{\mathrm{d}}$, Carlo Marchesi ${ }^{\mathrm{a}, \mathrm{b}}$ \\ a Department of Neuroscience, Psychiatry Unit, University of Parma, Parma, Italy \\ ${ }^{\mathrm{b}}$ Mental Health Department, AUSL, Parma, Italy

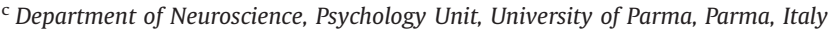 \\ ${ }^{\mathrm{d}}$ Department of Cardiology, University Hospital, Parma, Italy
}

\section{A R T I C L E I N F O}

\section{Article history:}

Received 19 January 2015

Received in revised form

6 May 2015

Accepted 25 May 2015

Available online 27 June 2015

\section{Keywords:}

Major depression

Minor depression

Positive affect

Anxiety

Women

Widowed

\begin{abstract}
A B S T R A C T
The association between depression and acute coronary syndrome (ACS) is well-established and the first seems to impact meaningfully on cardiac prognosis. Nonetheless only a few studies have evaluated the relationship between incident depression, defined as new cases in patients with no history of depression, and ACS. Therefore the aim of this study is to analyse the risk factors of incident depression in a sample of patients who were presenting their first ACS. 304 consecutive patients were recruited. The presence of major (MD) and minor (md) depression was assessed with the Primary Care Evaluation of Mental Disorders (PRIME-MD), whereas its severity was evaluated with the Hospital Anxiety and Depression Scale (HADS). Evaluations were collected both at baseline and at 1, 2, 4, 6, 9 and 12 month follow ups. Out of 304 subjects ( $80.6 \%$ males), MD was diagnosed in 15 (4.9\%) and md in 25 patients (8.2\%). At baseline risk factors for a post-ACS depressive disorder were being women (MD only), widowed (md only) and having mild anhedonic depressive symptoms few days after the ACS. Clinicians should keep in mind these variables when facing a patient at his/her first ACS, given the detrimental effect of depression on cardiac prognosis.
\end{abstract}

(c) 2015 Elsevier Ireland Ltd. All rights reserved.

\section{Introduction}

The association between depression and acute coronary syndrome (ACS) is well-established (Hare et al., 2014).

Depression in patients with ACS is associated with a worse cardiac outcome (Lichtman et al., 2014) due to an increase recurrence of cardiac events and mortality (Nicholson et al., 2006).

Risk factors for the development of depression after ACS have been also identified: younger age (Lespérance et al., 1996; Dickens et al., 2004; van Melle et al., 2006); female gender (Doyle et al., 2015); low level of education (Frasure-Smith et al., 2007; Carney et al., 2009); low socio-economic status (Steptoe et al., 2011); having no close friend (Frasure-Smith et al., 2000); being unemployed and living alone (Larsen et al., 2013; Spijkerman et al., 2005a); Type D personality (Martens et al., 2008); psychological vulnerabilities (i.e. exhaustion, fatigue, interpersonal difficulties, cognitive distortions) (Ladwig et al., 1992; Ketterer et al., 1998;

\footnotetext{
* Correspondence to: Department of Neuroscience, Psychiatry Unit, University of Parma, University Hospital, Braga Building. 43126 Parma, Italy. Fax: + 390521396825.

E-mail address: paolo.ossola@unipr.it (P. Ossola).
}

Strik et al., 2001; Rieckmann et al., 2006; Stafford et al., 2009; Doyle et al., 2011; Denton et al., 2012) and the presence of depressive symptoms in the few days after an ACS (Di Benedetto et al., 2007; Celano et al., 2012; Marchesi et al., 2014a).

The severity of the ACS has been proposed as another risk factor for developing depression; however, this association was found by some authors (van Melle et al., 2006; Frasure-Smith et al., 1999; de Jonge et al., 2006) and not by others (Lane et al., 2005; Lett et al., 2008).

Depression after ACS can be distinguished in two types: a postACS depressive episode in patients who have never been depressed before (incident depression) and depression that was present at the time of the ACS or already before (non-incident depression). Little is known about the aetiology and characteristics of incident depression and it remains unclear to what extent it should be considered a transient distress reaction to a life-threatening event (Lloyd and Cawley, 1982; Spijkerman et al., 2005b).

Few studies assessed risk factors specifically for incident depression in cardiac population. Contrasting results emerged regarding the severity of the ACS, where some studies observed this effect (Spijkerman et al., 2005a; Freedland et al., 1992) and other did not (Lespérance et al., 1996; Dickens et al., 2008). In other 
studies, female gender, younger age (Dickens et al., 2008), physical inactivity, abnormal body mass, drinking and smoking (Almeida et al., 2013; Doyle et al., 2014) seem to increase the risk for incident depression, whereas other authors did not find differences between those who developed incident depression and those who did not (Lloyd and Cawley, 1983).

To our knowledge only one study (Lloyd and Cawley, 1983) have evaluated the risk factors for incident depression in patients after their first ACS, whereas the others examined patients with a long lasting history of heart disease (Almeida et al., 2013; Lespérance et al., 1996; Spijkerman et al., 2005a; Dickens et al., 2008).

The importance of recognising ACS patients at risk of developing depression (Lim, 2014) is undeniable. In fact, even though incident depression is expected to be less severe (Freedland et al., 1992) and to remit spontaneously (Brown, 1988), it exerts the most negative effect on cardiac outcome (Carney et al., 2009; de Jonge et al., 2006; Dickens et al., 2008; Parker et al., 2008; Goodman et al., 2008; Zuidersma et al., 2011). Therefore, the identification of risk factor for incident depression, as to aim of this study, is particularly relevant in patients at their first ACS episode.

\section{Method}

The Local Ethics Committee approved the study protocol and the study was conducted according to the Helsinki Declaration. All the subjects provided informant consent after the study was fully explained.

\subsection{Sample}

The study sample was selected among patients who were consecutively admitted to the Coronary Intensive Care Unit of the University Hospital of Parma from January 2009 to March 2012, for an ACS.

All the subjects had no previous or current major depressive episode according DSM-IV (American Psychiatric Association, 1994) and they presented for the first time with symptoms suggestive of an acute coronary syndrome.

Cardiac condition at the enrolment were presenting for the first time with symptoms suggestive of an acute coronary syndrome and in whom a ST-segment elevation myocardial infarction (STEMI), a non-ST-segment elevation myocardial infarction (NSTEMI), or unstable angina had been diagnosed (Van deWerf et al. 2008; Hamm et al., 2011). The working diagnosis of NSTE-ACS was a rule-out diagnosis based on the ECG, i.e. lack of persistent ST elevation. Biomarkers (troponins) further distinguished NSTEMI and unstable angina (Hamm et al., 2011).

Moreover, the inclusion criteria were: (1) age over 18 years; (2) being native Italian speaker or with a proficiency in Italian and not showing cognitive impairment (Mini Mental State Examination (MMSE) > 25) (Folstein et al., 1975); (3) no substance abuse or dependence and not taking any psychotropic medication.

\subsection{Assessment}

All patients underwent the following evaluations at baseline: (1) a brief sociodemographic interview; (2) the Primary Care Evaluation of Mental Disorder (PRIME-MD) (Spitzer et al., 1994); (3) the Hospital Anxiety and Depression Scale (HADS) (Zigmond and Snaith, 1983). At baseline, patients were also interviewed by an expert psychiatry to confirm if the PRIME-MD answers fit their clinical condition and to exclude the presence of previous MD episodes.

The PRIME-MD and the HADS were re-administered to all patients after one, two, four, six and twelve months by the same trained psychiatrist.

The PRIME-MD is a structured interview designed to diagnose mental disorder according DSM-IV. The PRIME-MD evaluates the presence of 9 depressive symptoms in the last two weeks. Each symptom is rated on a four-point scale (from "not at all" to "most days"). Moreover, the PRIME-MD also rates on a four-point scale the difficulty in daily functioning due to the depressive symptoms (from "not at all" to "extremely difficult"). The PRIME-MD has showed good specificity (98\%) and sensitivity (73\%) in detecting MD in primary care (Spitzer et al., 1999). According to the PRIME-MD, a patient was defined depressed if, at any evaluation time, he/she fulfilled the criteria for a major depressive episode (MD) or a minor depressive episode (md). A patient was defined non-depressed if he or she did not satisfy the criteria for MD or md at any evaluation time during the follow-up period. Patients who had at least one MD or md episode over the follow up (regardless of the number of episodes) were classified, respectively, as MD and md. One patient who developed both MD and md episodes, at different time points, was included in the MD group only.

The HADS is a 14-items self-administered instrument for the evaluation of anxiety and depression in non-psychiatric samples. Each item is rated on a fivepoint (0-4) scale. The seven items of the depression subscale are largely based on the anhedonic state: in fact, five items are related to the loss of pleasure. The seven items of the anxiety subscale were chosen from the psychic manifestations of anxiety. Therefore, HADS generates two subscale scores: the anxiety score (HADS-A) and the depression score (HADS-D). HADS has been considered more consistent in evaluating depression, containing less somatic symptoms that could be more influenced by health status in ACS patients (Doyle et al., 2006).

One strategy for addressing the issue of potential clinical confounders is to utilize an evidence-based prediction tool to assess mortality risk after acute coronary events (Kronish et al., 2009). The Global Registry of Acute Coronary Events (GRACE) score (Eagle et al., 2004) is based on a risk model of 6 months mortality risk from the time of hospital discharge; it considers age, history of MI, past or current congestive heart failure (CHF), heart rate, systolic blood pressure, serum creatinine, elevated cardiac enzymes, ST-segment depression on ECG at admission, and no in hospital percutaneous intervention (PCI). All the information concerning the abovementioned parameters was obtained from chart review at baseline. The GRACE score ranges between 1 and 263 points. A score of 80 predicts a $1 \%$ mortality rate at six months, 100 predicts a $2 \%$ mortality rate, and $>210$ predicts a $>50 \%$ mortality rate.

\subsection{Treatment}

Concerning treatment of depression, patients with depressive symptoms were referred to a psychiatrist and properly treated.

\subsection{Statistical analyses}

After computing the rates of patients classified as MD, md, and never-depressed over the course of follow-up, the baseline differences among groups were evaluated using Fisher's exact test for categorical variables and one-way ANOVA with Bonferroni correction for continuous variables (i.e. age and HADS)

We then tested in two enter-method logistic regression (dependent variables md and MD vs. no depression) the best predicting model among the socio-demographic and clinical variables, which differed within groups at baseline. Specifically age, gender, being widowed, occupation, GRACE-score, HADS depression and HADS anxiety have been entered as independent variables to evaluate the prediction of the development of a depressive disorder during the follow-up period. We carried out all the analysis using SPSS software (version 21.0, IBM SPSS Statistics).

\section{Results}

\subsection{Patient characteristics}

Three-hundred-and-ninety-seven patients met the inclusion criteria, and among them, 377 agreed to participate in the study. During the follow-up period 25 moved outside the study area, 23 refused further psychiatric evaluations, 4 passed away and 21 continued the rehabilitation treatment in a different hospital. The study sample, therefore, included 304 subjects, 245 male (80.6\%) and 59 female (19.5\%), with a mean age of $61.4 \pm 10.9$ years (range $32-87$ years). Data regarding part of the study sample $(n=250$; follow-up period $=6$ months) has been considered in a previous study (Marchesi et al., 2014a).

\subsection{Depressive disorder}

Throughout the follow-up period, MD was diagnosed in 15 patients (4.9\%) and $\mathrm{md}$ in 25 patients $(8.2 \%)$, whereas 264 (86.8\%) did not developed a depressive disorder in the 12 months of follow-up.

More female were found within depressed, both MD and md, than in non-depressed subjects, whereas widowed status, living alone and being a housewife were more frequent in md than in non-depressed subjects (Table 1). GRACE score was significantly higher in the mo group than in MD group (Table 1).

\subsection{Severity of anxiety and depressive symptoms}

At baseline HADS-D score was significantly higher in subjects 
who developed MD during follow-up than in subjects who maintained a non-depressed condition. In contrast, HADS-A scores were similar in all groups of subjects (Table 1).

\subsection{Predictors of development of a depressive disorder}

Since a high correlation has been found between HADS-A and HADS-D $(r=.777, p<0.001)$ we tested the collinearity between the predictors and all the Tolerance Values were higher than 0.01 (Menard, 1995) and VIF Values smaller than 10 (Myers, 1990), with no huge differences in the Condition Indexes. Nonetheless, $91 \%$ of the variance of HADS-A and $80 \%$ of the variance of HADS-D were explained by the same small eigenvalue, suggesting that their regression coefficient could be dependent. We then performed an Exploratory Factor Analysis identifying two main factors at HADS: a first factor named negative affectivity that include low mood and worries (items 1, 3, 5, 6, 8, 10, 11 and 13) and a second factor named loss of positive affect and anxious arousal (items 2, 4, 7, 9, 12 and 14). Repeating the regression no collinearity emerged using these two factors and, then, the second factor, as much as being widowed emerged as predictors of incident minor depressive episodes whereas the second factor and being women resulted as predictor of MD (Table 2).

Of note, although not supported by a literature background, we arbitrary split the HADS in three factors: Positive Affect (items 2, 4, 10, 12 and 14), Negative Affect (items 1, 5, 6 and 8) and Anxious Arousal (items 3, 7, 9, 11 and 13). Given the arbitrary tricothomization of HADS we simply report the results of the regression analysis. Controlling for gender and widowhood for MD and md respectively, loss of positive affect resulted as a risk factor for incident $\mathrm{MD} \quad(\mathrm{OR}=1.69 ; 95 \% \mathrm{CI}=1.32-2.16 ; \quad p<.001)$ and $\mathrm{md}$ $(\mathrm{OR}=1.25 ; 95 \% \mathrm{IC}=1.03-1.50 ; p=0.018)$. Interestingly, underlying the possible protective role of anxiety, the factor Anxious Arousal resulted significantly and negatively associated with the development of $\mathrm{MD}(\mathrm{OR}=0.69 ; 95 \% \mathrm{CI}=0.51-0.95 ; p=0.023)$.

\section{Discussion}

The present study aimed to evaluate which socio-demographic and clinical features may represent risk factors for incident depression in patients at their first ACS.

Since incident and non-incident depression can be considered as different clinical entities both from symptoms, treatment response and outcome (Goodman et al., 2008) our results could address clinician in a more specific approach to never depressed patients at their first ACS episode. Furthermore, identifying risk factors will contribute to understanding the aetiology of incident depression (Spijkerman et al., 2005a).

The present study found that among patients experiencing their first ACS, women, widowed and those with loss of positive affectivity and anxiety a few days after the ACS, were at higher risk of suffering incident depression.

\subsection{Socio-demographic characteristics}

Our results partly confirm the risk factor of depression observed in the late life general population. As previously noticed widowhood is frequently associated with social isolation (Nicholson, 2012), lack of social support or living alone, which are themselves risk factors for depression. Moreover, being widowed (Steptoe et al., 2011), as female gender (Doyle et al., 2015) or being a housewife (Larsen et al., 2013), could be associated with a low socio-economic status, which represents a vulnerability to depression after a life event (Kendler et al., 2002).

Concerning gender, previous studies found that women are at

Table 1

Socio-demographic characteristics of patients distinguished according to their condition (MD, md, no depression).

\begin{tabular}{|c|c|c|c|c|c|}
\hline & $\begin{array}{l}\text { Major depression } \\
\text { n. } 15\end{array}$ & $\begin{array}{l}\text { Minor depression } \\
\text { n. } 25\end{array}$ & $\begin{array}{l}\text { No depression } \\
\text { n. } 264\end{array}$ & & \\
\hline Gender (female) & $5(33.3 \%)$ & $9(36.0 \%)$ & $45(17.0 \%)$ & $F=7.2$ & $p=0.02$ \\
\hline Age (years) & $62.2 \pm 11.8$ & $64.1 \pm 11.8$ & $61.1 \pm 10.8$ & $F=0.89$ & $p=0.40$ \\
\hline Education & & & & $F=1.5$ & $p=0.94$ \\
\hline Primary school & $3(20.0 \%)$ & $5(20.0 \%)$ & $37(14.1 \%)$ & & \\
\hline Secondary school & $6(40.0 \%)$ & $11(44.0 \%)$ & $101(38.4 \%)$ & & \\
\hline College graduated & $5(33.3 \%)$ & $7(28.0 \%)$ & $102(38.8 \%)$ & & \\
\hline University graduated & $1(6.7 \%)$ & $2(8.0 \%)$ & $23(8.7 \%)$ & & \\
\hline Family status & & & & $F=37.0$ & $p<0.001$ \\
\hline Never married & $2(13.3 \%)$ & $2(8.0 \%)$ & $32(12.1 \%)$ & & \\
\hline Married/Living together & $10(66.7 \%)$ & $12(48.0 \%)$ & $201(76.1 \%)$ & & \\
\hline Separated/Divorced & $2(13.3 \%)$ & $2(8.0 \%)$ & $20(7.6 \%)$ & & \\
\hline Widowed & $1(6.7 \%)$ & $9(36.0 \%)$ & $11(4.2 \%)$ & & \\
\hline Living alone & $3(20.0 \%)$ & $8(32.0 \%)$ & $41(15.5 \%)$ & $F=4.4$ & $p=0.09$ \\
\hline Occupation & & & & $F=17.5$ & $p=0.01$ \\
\hline Unemployed & 0 & $2(8.0 \%)$ & $6(2.3 \%)$ & & \\
\hline Retired & $7(46.7 \%)$ & $12(48.0 \%)$ & $131(49.6 \%)$ & & \\
\hline Housewife & 0 & $5(20.0 \%)$ & $11(4.2 \%)$ & & \\
\hline Employed & $8(53.3 \%)$ & $6(24.0 \%)$ & $116(43.9 \%)$ & & \\
\hline BMI & $27.6 \pm 4.2$ & $26.9 \pm 3.8$ & $27.5 \pm 4.2$ & $F=0.13$ & $p=0.88$ \\
\hline Cigarettes/day & $5 \pm 10.2$ & $2.6 \pm 5.84$ & $7.42 \pm 11.6$ & $F=2.1$ & $p=0.13$ \\
\hline Grace score & $116.4 \pm 23.3$ & $143.4 \pm 30.3$ & $129.7 \pm 29.1$ & $F=4.4$ & $p=0.01^{*}$ \\
\hline HADS Anxiety at baseline & $9.7 \pm 2.3$ & $8.7 \pm 4.9$ & $9.1 \pm 5.2$ & $F=0.16$ & $p=0.84$ \\
\hline HADS Depression at baseline & $9.9 \pm 3.6$ & $7.8 \pm 4.1$ & $6.8 \pm 4.2$ & $F=4.2$ & $p<0.001$ \\
\hline
\end{tabular}

HADS-D: Hospital Anxiety and Depression Scale-Depression, HADS-A: Hospital Anxiety and Depression Scale-Anxiety; $F=$ ANOVA with Bonferroni post-hoc analysis: $* \mathrm{dm}>\mathrm{DM}$. 
Table 2

Significant baseline predictors of incident depression during the year following the first episode of acute coronary syndrome.

\begin{tabular}{|c|c|c|c|c|c|}
\hline & B & $\chi^{2}$ wald & OR & CI 95\% & $p$ \\
\hline \multicolumn{6}{|l|}{$\begin{array}{l}\text { Minor depression vs. no } \\
\text { depression }\end{array}$} \\
\hline Being widowed & 2.32 & 10.87 & 10.18 & $2.57-40.42$ & $<0.001$ \\
\hline $\begin{array}{l}\text { Loss of positive affectivity and } \\
\text { anxious arousal }\end{array}$ & 0.51 & 5.82 & 1.67 & $1.10-2.53$ & 0.01 \\
\hline \multicolumn{6}{|l|}{$\begin{array}{l}\text { Major depression vs No } \\
\text { depression }\end{array}$} \\
\hline $\begin{array}{l}\text { Loss of positive affectivity and } \\
\text { anxious arousal }\end{array}$ & 1.14 & 18.95 & 3.13 & $1.87-5.23$ & $<0.001$ \\
\hline Female & 1.26 & 3.94 & 3.5 & $1.02-12.05$ & 0.04 \\
\hline
\end{tabular}

Independent variables: age, gender, widowhood, GRACE-score, occupation, HADS factors (i.e. negative affect and loss of positive affectivity and anxious arousal). Minor depression vs. no depression:

$R^{2}=0.21$ (Nagelkerke), 0.16 (Hosmer and Lemeshow), Model $\chi^{2}=21.66 ; p<0.001$. Major depression vs. no depression:

$R^{2}=0.24$ (Nagelkerke), 0.21 (Hosmer and Lemeshow), Model $\chi^{2}=23.51 ; p<0.001$.

higher risk of in-hospital depression (Martens et al., 2008), which is consistent with the results of recent meta-analysis (Rutledge et al., 2006; Doyle et al., 2015). This finding could be partly explained by a reduced access to care of women after premature acute coronary syndrome that result in a poorer outcome (Choi et al., 2014). Instead, our results, do not confirm the findings of previous studies that evaluating only incident depression (Dickens et al., 2008; Lossnitzer et al., 2013), did not find gender as risk factor for the development of depression after ACS in never depressed subjects.

The association of widowhood with md only, instead, could underlie the reactive characteristic of this specific type of depression after a major life event (i.e., ACS) (Marchesi et al., 2014b).

Conversely to our findings, some studies found a trend of younger age predicting post-ACS depression (Lespérance et al., 1996; Dickens et al., 2004; van Melle et al., 2006). The lack of this result could reflect our sample's characteristics in which all the patients have no history of depression, whereby patients with history of depression are younger when first hospitalized for an ischemic event (Parker et al., 2008).

\subsection{ACS severity}

In our study the severity of cardiovascular conditions expressed as risk of mortality at 6 months (GRACE score) did not represent an independent risk factor for incident depression. No previous studies evaluated the association between GRACE score and incident depression. The only two studies that employed the GRACE score independently from the onset of depression (Kronish et al., 2009; Meurs et al., 2013) found contrasting results. One (Meurs et al., 2013) observed a positive relationship only with the somatic/affective subset of depressive symptoms whereas the other, despite the differences in GRACE-score between depressed and no depressed subjects, did not find any association between depressive measures and overall GRACE-score. Even though patients with md scored higher at GRACE-score than patients with MD or non-depressed $(\mathrm{MD}=116.4 \pm 23.3 ; \mathrm{md}=143.4 \pm 30.3$; non-depressed $=$ $129.7 \pm 29.1 ; F=4.4 ; p=0.01 ;$ Cohen's $d=0.470)$, in regression analysis, adding GRACE-score did not improve significantly the model.

\subsection{Baseline depressive and anxious symptoms}

In the present study, patients with loss of positive affectivity (i.e., "I still enjoy the things I used to", "I can laugh and see the funny side of things", "I look forward with enjoyment to things" and "I can enjoy a good TV or radio program or book") in the first days after ACS were at higher risk of major and minor incident depression, confirming previous studies evaluating incident (Marchesi et al., 2014a) and non-incident depression after ACS (Lespérance et al., 1996; Lossnitzer et al., 2013).

Although is well recognized the poor response to treatment in depressed patients with high level of anxiety (Altamura et al., 2004), as much as the negative impact of anxiety on cardiac outcome (Roest et al., 2010) the role of anxiety in predicting depression in cardiac population is still unclear.

Two previous studies found that anxious patients were at higher risk for developing depression (Di Benedetto et al., 2007; Celano et al., 2012) whereas few more studies found an inverse association between baseline anxiety and cardiac outcome (Ketterer et al., 1998; Herrmann et al., 2000; Parker et al., 2010, 2011; Benyamini et al., 2013) leading to the conclusion that maybe it's "time to start worrying" (Parker et al., 2010). Indeed, these authors conclude that baseline anxiety after an ACS has a protective role on cardiac outcome and subsequent cardiac events. From this point of view there could be three possible explanations: (1) anxiety may have a positive effect by promoting protective health behaviours such as seeking help at early signs of disease, taking medications more regularly, and being more demanding and proactive with their health practitioner (Herrmann et al., 2000; Parker et al., 2010; Benyamini et al., 2013); (2) After an ACS, reacting with anxiety as a result of having faced death could motivate patients to change their lifestyle (Havik and Maeland, 1988) and proactively reduce stress; (3) on the other hand, as much as anxiety is the natural response to a stressful life event, like ACS, denial of it (Ketterer et al., 1998), mediated by inefficient coping styles (Di Benedetto et al., 2007), could predispose the patient towards the development of depression.

Our data suggest that two anxious items (i.e. "I can seat at ease and feel relaxed" and "I get a sort of frightened feeling like butterflies in the stomach"), which segregated in the same factor together with the items of loss of positive affectivity, could predict incident depression suggesting a role of anxious tension as a risk factor for the development of depression after ACS in never depressed subjects whereas in our sample anxious worries were not a risk factors for incident depression.

Interestingly, in the present study the above-mentioned classification of depressive and anxious symptoms obtained with exploratory analysis reflects, with the limits of the domains explored by HADS, the tripartite model (negative affectivity, loss of positive affectivity and anxious arousal) of depression and anxiety proposed by Clark and Watson (Clark and Watson, 1991). In fact, the first factor overlap with some aspects of negative affectivity (i.e. low mood and psychic anxiety) and the second include both the lack of positive affect and the anxious arousal. Moreover, this approach seems particularly relevant according recent literature both regarding cardiac prevention (Meyer et al., 2014) and in light of the recent debates concerning the ability of HADS in discerning depression and anxiety (Coyne and van Sonderen, 2012; Cosco et al., 2012; Norton et al., 2013; Burns et al., 2014).

\subsection{Limitations}

This study has some limitations. Firstly, the small number of depressed patients in this sample limits the reliability of our results and increases the risk of over-fitting, although the exclusion of patients with previous depressive episode allows us to infer 
stronger conclusions about risk factors for incident depression.

Similarly, the fact that patients were experiencing their first ACS, allows us to exclude any effects previous long-lasting or more severe forms of coronary artery disease might have on the onset of the current depressive episode.

Secondly, our sample includes mostly male patients, thus limiting this study's applicability to females, who might have different risk factors in terms of developing depression.

Thirdly, the retrospective assessment of historical depressive disorder might have been biased by current post-MI depressive symptoms (Ben-Zeev and Young, 2010). Nevertheless, in our sample a psychiatrist evaluated the clinical history in all cases, reducing the probability of misdiagnosis.

Finally, some potential predictors, like personality vulnerabilities and coping styles have not been considered in the present study.

\subsection{Conclusion}

Within these limitations, our results suggest that widowed subjects and people with loss of positive affectivity and somatic anxious features in the first few days after their first ACS are at higher risk of developing incident depression. This suggest the possibility to consider different treatments (Tomarken et al., 2004; Gerra et al., 2014) when facing somehow distinct depressive disorders (Goodman et al., 2008). Collectively, our data suggest to clinician to keep in mind these variables, and administer a quick questionnaire as HADS, when facing a patient at his or her first ACS, given the detrimental effect of depression on cardiac prognosis.

\section{Acknowledgements}

All authors declare no Conflicts of Interest and Source of Funding.

\section{References}

Almeida, O.P., Hankey, G.J., Yeap, B.B., Golledge, J., McCaul, K., Flicker, L., 2013. A risk table to assist health practitioners assess and prevent the onset of depression in later life. Prev. Med. 57, 878-882. http://dx.doi.org/10.1016/j.

ypmed.2013.09.021,, 878-882. http://dx.doi.org/10.1016/j.ypmed.2013.09.021.

Altamura, A.C., Montresor, C., Salvadori, D., Mundo, E., 2004. Does comorbid subthreshold anxiety affect clinical presentation and treatment response in depression? A preliminary 12-month naturalistic study. Int. J. Neuropsychopharmacol. 7, 481-487.

American Psychiatric Association, 1994. Diagnostic and Statistical Manual of Mental Disorders, 4th edn..

Benyamini, Y., Roziner, I., Goldbourt, U., Drory, Y., Gerber, Y., 2013. Depression and anxiety following myocardial infarction and their inverse associations with future health behaviors and quality of life. Ann. Behav. Med. 46, 310-321.

Ben-Zeev,, D., Young, M., A., 2010. Accuracy of hospitalized depressed patients' and healthy controls' retrospective symptom reports: an experience sampling study. J. Nerv. Ment. Dis. 198, 280-285.

Brown, W.A., 1988. Predictors of placebo response in depression. Psychopharmacol. Bull. 24, 14-17.

Burns, A., Höfer, S., Curry, P., Sexton, E., Doyle, F., 2014. Revisiting the dimensionality of the Hospital Anxiety and Depression Scale in an international sample of patients with ischaemic heart disease. J. Psychosomat. Res. 77, 116-121. http: //dx.doi.org/10.1016/j.jpsychores.2014.05.005,, 116-121. http://dx.doi.org/ 10.1016/j.jpsychores.2014.05.005.

Carney, R.M., Freedland, K.E., Steinmeyer, B., Blumenthal, J.A., de Jonge, P., Davidson, K.W., Czajkowski, S.M., Jaffe, A.S., 2009. History of depression and survival after acute myocardial infarction. Psychosomat. Med. 71, 233-239. http://dx.doi.org/ 10.1097/PSY.0b013e31819b69e3.

Celano, C.M., Mastromauro, C.A., Lenihan, E.C., Januzzi, J.L., Rollman, B.L., Huffman, J. C., 2012. Association of baseline anxiety with depression persistence at 6 months in patients with acute cardiac illness. Psychosomat. Med. 74, 93-99. http://dx.doi.org/10.1097/PSY.0b013e31823d38bc.

Choi, J., Daskalopoulou, S.S., Thanassoulis, G., Karp, I., Pelletier, R., Behlouli, H., Pilote, L., 2014. GENESIS-PRAXY Investigators. Sex- and gender-related risk factor burden in patients with premature acute coronary syndrome. Can. J. Cardiol. 30, $109-117$.
Clark, L.A., Watson, D., 1991. Tripartite model of anxiety and depression: psychometric evidence and taxonomic implications. J. Abnorm. Psychol. 100, 316-336.

Cosco, T.D., Doyle, F., Ward, M. McGee, H., 2012. Latent structure of the Hospital Anxiety And Depression Scale: a 10-year systematic review. J. Psychosomat. Res. 72 (3), 180-184. http://dx.doi.org/10.1016/j.jpsychores.2011.06.008.

Coyne, J.C., van Sonderen, E., 2012. No further research needed: abandoning the Hospital and Anxiety Depression Scale (HADS). J. Psychosomat. Res. 72 (3), 173-174, doi:0.1016/j.jpsychores.2011.12.003.

de Jonge, P., van den Brink, R.H., Spijkerman, T.A., Ormel, J., 2006. Only incident depressive episodes after myocardial infarction are associated with new cardiovascular events. J. Am. Coll. Cardiol. 48, 2204-2208.

Denton, E.G., Rieckmann, N., Davidson, K.W., Chaplin, W.F., 2012. Psychosocial vulnerabilities to depression after acute coronary syndrome: the pivotal role of rumination in predicting and maintaining depression. Front. Psychol. 3, 288 http://dx.doi.org/10.3389/fpsyg.2012.00288, eCollection 2012.

Di Benedetto, M., Lindner, H., Hare, D.L., Kent, S., 2007. The role of coping, anxiety, and stress in depression post-acute coronary syndrome. Psychol. Health Med. $12,460-469$.

Dickens, C., McGowan, L., Percival, C., Tomenson, B., Cotter, L., Heagerty, A., Creed, F. 2008. New onset depression following myocardial infarction predicts cardiac mortality. Psychosomat. Med. 70, 450-455. http://dx.doi.org/10.1097/ PSY.0b013e31816a74de.

Dickens, C.M., Percival, C., McGowan, L., Douglas, J., Tomenson, B., Cotter, L., Heagerty, A., Creed, F.H., 2004. The risk factors for depression in first myocardial infarction patients. Psychol. Med. 34, 1083-1092.

Doyle, F., McGee, H.M., De La Harpe, D., Shelley, E., Conroy, R., 2006. The Hospital Anxiety and Depression Scale depression subscale, but not the Beck Depression Inventory-Fast Scale, identifies patients with acute coronary syndrome at elevated risk of 1-year mortality. J. Psychosomat. Res. 60, 461-467.

Doyle, F., McGee, H., Delaney, M., Motterlini, N., Conroy, R., 2011. Depressive vulnerabilities predict depression status and trajectories of depression over 1 year in persons with acute coronary syndrome. Gen. Hosp. Psychiatry 33, 224-231. http://dx.doi.org/10.1016/j.genhosppsych.2011.03.008.

Doyle, F., Rohde, D., Rutkowska, A., Morgan, K., Cousins, G., McGee, H., 2014. Systematic review and meta-analysis of the impact of depression on subsequent smoking cessation in patients with coronary heart disease: 1990 to 2013. Psychosomat. Med. 76, 44-57. http://dx.doi.org/10.1097/ PSY.0000000000000020.

Doyle, F., McGee, H., Conroy, R., Conradi, H.J., Meijer, A., Steeds, R., Sato, H., Stewart D.E., Parakh, K., Carney, R., Freedland, K., Anselmino, M., Pelletier, R., Bos, E.H., de Jonge, P., 2015. Systematic review and individual patient data meta-analysis of sex differences in depression and prognosis in persons with myocardial infarction: a MINDMAPS study. Psychosomat. Med. [Epub ahead of print]

Eagle, K.A., Lim, M.J., Dabbous, O.H., Pieper, K.S., Goldberg, R.J., Van de Werf, F., Goodman, S.G., Granger, C.B., Steg, P.G., Gore, J.M., Budaj, A., Avezum, A., Flather M.D., Fox, K.A., 2004. A validated prediction model for all forms of acute coronary syndrome: estimating the risk of 6-month postdischarge death in an international registry. J. Am. Med. Assoc. 291, 2727-2733.

Folstein, M.F., Folstein, S.E., McHugh, P.R., 1975. "Mini-mental state”. A practical method for grading the cognitive state of patients for the clinician. J. Psychiatric Res. 12, 189-198.

Frasure-Smith, N., Lespérance, F., Gravel, G., Masson, A., Juneau, M., Talajic, M. Bourassa, M.G., 2000. Social support, depression, and mortality during the first year after myocardial infarction. Circulation 101, 1919-1924.

Frasure-Smith, N., Lespérance, F., Irwin, M.R., Sauvé, C., Lespérance, J., Théroux, P. 2007. Depression, C-reactive protein and two-year major adverse cardiac events in men after acute coronary syndromes. Biol. Psychiatry 62, 302-308.

Frasure-Smith, N., Lespérance, F., Juneau, M., Talajic, M., Bourassa, M.G., 1999. Gender, depression, and one-year prognosis after myocardial infarction. Psychosomat. Med. 61, 26-37.

Freedland, K.E., Carney, R.M., Lustman, P.J., Rich, M.W., Jaffe, A.S., 1992. Major depression in coronary artery disease patients with vs. without a prior history of depression. Psychosomat. Med. 54, 416-421.

Gerra, M.L., Marchesi, C., Amat, J.A., Blier, P., Hellerstein, D.J., Stewart, J.W., 2014 Does negative affectivity predict differential response to an SSRI versus a nonSSRI antidepressant? J. Clin. Psychiatry 75, e939-e944.

Goodman, J., Shimbo, D., Haas, D.C., Davidson, K.W., Rieckmann, N., 2008. Incident and recurrent major depressive disorder and coronary artery disease severity in acute coronary syndrome patients. J. Psychiatric Res. 42, 670-675.

Hamm, C.W., Bassand, J.P., Agewall, S., Bax, J., Boersma, E., Bueno, H., Caso, P., Dudek D., Gielen, S., Huber, K., Ohman, M., Petrie, M.C., Sonntag, F., Sousa Uva, M., Storey, R.F., Wijns, W., Zahger, D., 2011. The Task Force for the management of acute coronary syndromes (ACS) in patients presenting without persistent STsegment elevation of the European Society of Cardiology (ESC). ESC Guidelines for the management of acute coronary syndromes in patients presenting without persistent ST-segment elevation. Euro. Heart J., 32; , pp. 2999-3054.

Hare, D.L., Toukhsati, S.R., Johansson, P., Jaarsma, T., 2014. Depression and cardiovascular disease: a clinical review. Euro. Heart J. 35, 1365-1372.

Havik, O.E., Maeland, J.G., 1988. Changes in smoking behavior after a myocardial infarction. Health Psychol. 7, 403-420.

Herrmann, C., Brand-Driehorst, S., Buss, U., Rüger, U., 2000. Effects of anxiety and depression on 5-year mortality in 5,057 patients referred for exercise testing. J Psychosomat. Res. 48, 455-462.

Kendler, K.S., Gardner, C.O., Prescott, C.A., 2002. Toward a comprehensive developmental model for major depression in women. Am. J. Psychiatry 159, 1133-1145.

Ketterer, M.W., Huffman, J., Lumley, M.A., Wassef, S., Gray, L., Kenyon, L., Kraft, P., Brymer, J., Rhoads, K., Lovallo, W.R., Goldberg, A.D., 1998. Five-year follow-up for adverse outcomes in males with at least minimally positive angiograms: importance of "denial" in assessing psychosocial risk factors. J. Psychosomat. 
Res. 44, 241-250.

Kronish, I.M., Rieckmann, N., Schwartz, J.E., Schwartz, D.R., Davidson, K.W., 2009. Is depression after an acute coronary syndrome simply a marker of known prognostic factors for mortality? Psychosomat. Med. 71, 697-703.

Ladwig, K.H., Lehmacher, W., Roth, R., Breithardt, G., Budde, T., Borggrefe, M., 1992 Factors which provoke post-infarction depression: results from the post-infarction late potential study (PILP). J. Psychosomat. Res. 36, 723-729.

Lane, D., Ring, C., Lip, G.Y., Carroll, D., 2005. Depression, indirect clinical markers of cardiac disease severity, and mortality following myocardial infarction. Heart 91, 531-532.

Larsen, K.K., Christensen, B., Søndergaard, J., Vestergaard, M., 2013. Depressive symptoms and risk of new cardiovascular events or death in patients with myocardial infarction: a population-based longitudinal study examining health behaviors and health care interventions. PLoS One 8, e74393. http://dx.doi.org/ 10.1371/journal.pone.0074393.

Lespérance, F., Frasure-Smith, N., Talajic, M., 1996. Major depression before and after myocardial infarction: its nature and consequences. Psychosomat. Med. 58, 99-110.

Lett, H., Ali, S., Whooley, M., 2008. Depression and cardiac function in patients with stable coronary heart disease: findings from the Heart and Soul Study. Psychosomat. Med. 70, 444-449. http://dx.doi.org/10.1097/PSY.0b013e31816c3c5c.

Lichtman, J.H., Froelicher, E.S., Blumenthal, J.A., Carney, R.M., Doering, L.V., FrasureSmith, N., Freedland, K.E., Jaffe, A.S., Leifheit-Limson, E.C., Sheps, D.S., Vaccarino, V., Wulsin, L., 2014. American heart association statistics committee of the council on epidemiology and prevention and the council on cardiovascular and stroke nursing Depression as a risk factor for poor prognosis among patients with acute coronary syndrome: systematic review and recommendations: a scientific statement from the American Heart Association. Circulation 129, 1350-1369. http://dx.doi.org/10.1161/CIR.0000000000000019.

Lim, G.B., 2014. Risk factors: depression recognized as a risk factor in ACS. Nat. Rev. Cardiol. 11, 185.

Lloyd, G.G., Cawley, R.H., 1982. Psychiatric morbidity after myocardial infarction. Q. J. Med. $51,33-42$.

Lloyd, G.G. Cawley, R.H., 1983. Distress or illness? A study of psychological symptoms after myocardial infarction. Br. J. Psychiatry 142, 120-125.

Lossnitzer, N., Herzog, W., Störk, S., Wild, B., Müller-Tasch, T., Lehmkuhl, E., Zugck C., Regitz-Zagrosek, V., Pankuweit, S., Maisch, B., Ertl, G., Gelbrich, G., Angermann, C.E., 2013. Incidence rates and predictors of major and minor depression in patients with heart failure. Int. J. Cardiol. 167, 502-507.

Marchesi, C., Ossola, P., Scagnelli, F., Paglia, F., Aprile, S., Monici, A., Tonna, M., Conte, G., Masini, F., De Panfilis, C., Ardissino, D., 2014a. Type D personality in neverdepressed patients and the development of major and minor depression after acute coronary syndrome. J. Affect. Disord. 155, 194-199. http://dx.doi.org/ 10.1016/j.jad.2013.10.052.

Marchesi, C., Ampollini, P., Paraggio, C., Giaracuni, G., Ossola, P., De Panfilis, C., Tonna, M., Viviani, D., 2014b. Risk factors for panic disorder in pregnancy: a cohort study. J. Affect. Disord. 156, 134-138. http://dx.doi.org/10.1016/j. jad.2013.12.006.

Martens, E.J., Smith, O.R., Winter, J., Denollet, J., Pedersen, S.S., 2008. Cardiac history, prior depression and personality predict course of depressive symptoms after myocardial infarction. Psychol. Med. 38, 257-264.

Menard, S., 1995. Applied logistic regression analysis. Sage, vol 106;

Meurs, M., Zuidersma, M., Dickens, C., de Jonge, P., 2013. Examining the relation between post myocardial infarction depression and cardiovascular prognosis using a validated prediction model for post myocardial mortality. Int. J. Cardiol. 167, 2533-2538

Meyer, F.A., von Känel, R., Saner, H., Schmid, J.P. and Stauber, S., 2014. Positive affect moderates the effect of negative affect on cardiovascular disease-related hospitalizations and all-cause mortality after cardiac rehabilitation. Eur. J. Prev. Cardiol. [Epub ahead of print], http://dx.doi.org/10.1177/2047487314549745.

Myers, R., 1990. Classical and modern regression with applications, 2nd ed. Duxbury, Boston, MA.

Nicholson, A., Kuper, H., Hemingway, H., 2006. Depression as an aetiologic and prognostic factor in coronary heart disease: a meta-analysis of 6362 events among 146538 participants in 54 observational studies. Euro. Heart J. 27. 2763-2774.

Nicholson, N.R., 2012. A review of social isolation: an important but underassessed condition in older adults. J. Prim. Prev. 33, 137-152.
Norton, S., Cosco, T., Doyle, F., Done, J., Sacker, A., 2013. The Hospital Anxiety and Depression Scale: a meta confirmatory factor analysis. J. Psychosomat. Res. 74, 74-81. http://dx.doi.org/10.1016/j.jpsychores.2012.10.010.

Parker, G.B., Hilton, T.M., Walsh, W.F., Owen, C.A., Heruc, G.A., Olley, A., Brotchie, H., Hadzi-Pavlovic, D., 2008. Timing is everything: the onset of depression and acute coronary syndrome outcome. Biol. Psychiatry 64, 660-666. http://dx.doi. org/10.1016/j.biopsych.2008.05.021.

Parker, G., Hyett, M., Hadzi-Pavlovic, D., Brotchie, H., Walsh, W., 2011. GAD is good? Generalized anxiety disorder predicts a superior five-year outcome following an acute coronary syndrome. Psychiatry Res. 188, 383-389.

Parker, G.B., Owen, C.A., Brotchie, H.L., Hyett, M.P., 2010. The impact of differing anxiety disorders on outcome following an acute coronary syndrome: time to start worrying? Depress. Anxiety 27, 302-309.

Rieckmann, N., Burg, M.M., Gerin, W., Chaplin, W.F., Clemow, L., Davidson, K.W., 2006. Depression vulnerabilities in patients with different levels of depressive symptoms after acute coronary syndromes. Psychother. Psychosomatic 75, 353-361.

Roest, A.M., Martens, E.J., Denollet, J., de Jonge, P., 2010. Prognostic association of anxiety post myocardial infarction with mortality and new cardiac events: a meta-analysis. Psychosomat. Med. 72, 563-569.

Rutledge, T. Reis, V.A., Linke, S.E., Greenberg, B.H., Mills, P.., 2006. Depression in heart failure a meta-analytic review of prevalence, intervention effects, and associations with clinical outcomes. J. Am. Coll. Cardiol 48, 1527-1537.

Spijkerman, T., de Jonge, P., van den Brink, R.H., Jansen, J.H., May, J.F., Crijns, H.J., Ormel, J., 2005a. Depression following myocardial infarction: first-ever versus ongoing and recurrent episodes. Gen. Hosp. Psychiatry 27, 411-417.

Spijkerman, T.A., van den Brink, R.H., Jansen, J.H., Crijns, H.J., Ormel, J., 2005b. Who is at risk of post-MI depressive symptoms? J. Psychosomat. Res. 58, 425-434.

Spitzer, R.L., Kroenke, K., Williams, J.B., 1999. Validation and utility of a self-report version of PRIME-MD: the PHQ primary care study. Primary care evaluation of mental disorders. Patient Health Questionnaire. J. Am. Med. Assoc. 282, 1737-1744.

Spitzer, R.L., Williams, J.B., Kroenke, K., Linzer, M., deGruy III, F.V., Hahn, S.R., Brody, D., Johnson, J.G., 1994. Utility of a new procedure for diagnosing mental disorders in primary care. The PRIME-MD 1000 study. J. Am. Med. Assoc. 272, 1749-1756.

Stafford, L., Jackson, H.J., Berk, M., 2009. Cognitive-personality style as vulnerability to depression in patients with coronary artery disease: roles of sociotropy and autonomy. Psychosomatic Med. 71, 63-69. http://dx.doi.org/10.1097/PSY.0b013e318187c023,, 63-69. http://dx.doi.org/10.1097/PSY.0b013e318187c023.

Steptoe, A., Molloy, G.J., Messerly-Bürgy, N., Wikman, A., Randall, G., Perkins-Porras, L., Kaski, J.C., 2011. Emotional triggering and low socio-economic status as determinants of depression following acute coronary syndrome. Psychol. Med. 41, 1857-1866. http://dx.doi.org/10.1017/S0033291710002588.

Strik, J.J., Honig, A., Lousberg, R., van Os, J., van den Berg, E.J., van Praag, H.M., 2001. Clinical correlates of depression following myocardial infarction. International Journal Psychiatry. Int. J. Psychiatry Med. 31, 255-264.

Tomarken, A.J., Dichter, G.S., Freid, C., Addington, S., Shelton, R.C., 2004. Assessing the effects of bupropion SR on mood dimensions of depression. J. Affect. Disord. $78,235-241$

Van deWerf, F., Bax, J., Betriu, A., Blomstrom-Lundqvist, C., Crea, F., Falk, V., Filippatos, G., Fox, K., Huber, K., Kastrati, A., Rosengren, A., Steg, P.G., Tubaro, M., Verheugt, F., Weidinger, F. Weis, M. 2008, Management of acute myocardial infarction in patients presenting with persistent ST-segment elevation: the task force on the management of ST-segment elevation acute myocardial infarction of the European Society of Cardiology. Euro. Heart J. 29, 2909-2945.

van Melle, J.P., de Jonge, P., Kuyper, A.M., Honig, A., Schene, A.H., Crijns, H.J., van den Berg, M.P., van Veldhuisen, D.J., Ormel, J., 2006. Prediction of depressive disorder following myocardial infarction data from the Myocardial INfarction and Depression-Intervention Trial (MIND-IT). Int. J. Cardiol. 109, 88-94.

Zigmond, A.S., Snaith, R.P., 1983. The hospital anxiety and depression scale. Acta Psychiat. Scand. 67, 361-370.

Zuidersma, M., Thombs, B.D., de Jonge, P., 2011. Onset and recurrence of depression as predictors of cardiovascular prognosis in depressed acute coronary syndrome patients: a systematic review. Psychother. Psychosomat. 80, 227-237. http://dx.doi.org/10.1159/000322633. 